\title{
INDIVIDUAÇÃO E EXPERIÊNCIA RELIGIOSA EM EDITH STEIN
}

\author{
Individuation anda Religious experience in Edth Stein
}

\begin{abstract}
Ocir de Paula Andreata ${ }^{1}$ Uniandrade - Paraná/ Brasil

RESUMO: A individuação é o tema central da filosofia ontológica ocidental, que perpassa toda a história da formação do pensamento ocidental sobre a constituição do indivíduo e de sua enticidade, e chega ao Séc. XX renovado pela via da fenomenologia, e em especial pela reflexão ontológica da pensadora judia-cristã Edith Stein. O problema da individuação diz respeito ao processo de desenvolvimento da pessoa, no tempo e espaço histórico, enquanto processo de tornar-se si- mesmo. Em Edith Stein o processo de individuação, como passagem de uma essência que se atualiza e realiza no contínuo ato existencial da vida no mundo, inclui em si a experiência de espiritualidade pessoal, pois o viver no mundo exige a transcendência de si em direção ao sentido da vida. O objetivo deste ensaio é apresentar uma pequena síntese do conceito de individuação no pensamento de Edith Stein e uma síntese de sua trajetória pessoal e religiosa, como demonstração de realização do conceito em sua experiência própria. O método a ser utilizado na pesquisa é o de ensaio filosófico articulando o conceito e a experiência existencial da própria autora. A reflexão será apresentada no texto em dois tópicos, a saber: 1) O conceito de individuação em Edith Stein; 2) A experiência religiosa de Edith Stein. Como resultado, esperase poder apresentar uma síntese dos conceitos e demonstrar que a experiência pessoal da própria autora serve de exemplo ao estudo do tem.
\end{abstract}

Palavras-chave: Individuação. Existência. Experiência Religiosa.

ABSTRACT: The Individuation is the central theme of Western ontological philosophy, which runs through the history of the formation of Western thought on the constitution of the individual and his or her entity, and comes to the twentieth century renewed by the path of phenomenology, and especially by the ontological reflection of Jewish-Christian thinker Edith Stein. The problem of individuation concerns the process of the person's development in time and historical space as a process of becoming self. In Edith Stein the process of individuation, as a passage of an essence that is actualized and realized in the continuous existential act of life in the world, includes in itself the experience of personal spirituality, since to live in the world requires the transcendence of itself towards the sense of life. The purpose of this essay is to present a brief synthesis of the concept of individuation in Edith Stein's thought and a synthesis of her personal and religious trajectory as a demonstration of realization of the concept in her own experience. The method to be used in the research is the one of philosophical essay articulating the concept and the existential experience of the author herself. The reflection will be presented in the text in two topics, namely: 1) The concept of individuation in Edith Stein; 2) The religious experience of Edith Stein. As a result, it is hoped to be able to present a synthesis of the concepts and demonstrate that the personal experience of the author herself serves as an example to the study of the theme.

Keywords: Individuation. Existence. Religious Experience.

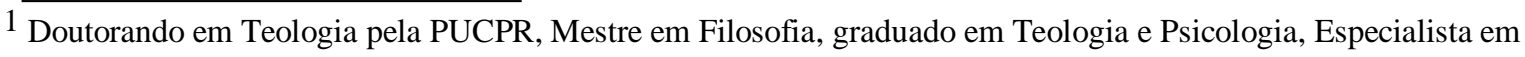
Sexologia, pesquisador sobre o tema da Individuação; professor da Universidade Uniandrade; e coordenador do Curso de Especialização em Sexualidade Humana, na Universidade Positivo/PR. E-mail: ocirandreta@gmail.com·
} 


\section{Introdução}

A individuação é a entelécheia ${ }^{1}$ do ser no tempo histórico e no mundo da vida, ou seja, a individuação é o processo de desenvolvimento do ser e da realização plena de si no mundo da vida, de modo individual e coletivo, tornando-se si mesmo como pessoa humana.

A problemática da individuação é o foco central da filosofia ontológica ocidental, tema que perpassa toda a história do pensamento, sendo compreendida de formas diferentes e complementares por vários pensadores, na medida do crescimento do interesse e da reflexão do tema juntamente com o desenvolvimento de sua epistemologia. O tema da individuação, portanto, vem desde a filosofia clássica grega e chega ao Séc. XX renovado pelo interesse de alguns fenomenólogos como Martin Heidegger e em especial por Edith Stein, que recoloca a transcendência como dimensão necessária à ontologia. E, ao contrário de Heidegger, Stein apresenta a busca da verdade do ser como a espiritualidade própria da pessoa que acontece em seu processo de individuação.

A individuação, enquanto processo mesmo do vir-a-ser do sujeito humano no mundo da vida, inexoravelmente encaminha o individuo à plena realização de si-mesmo. Neste percurso também se dá o fenômeno religioso, independente da tradição religiosa a que a pessoa esteja ligada ou não, mas especialmente a partir da experiência espiritual pessoal que se dá no âmago da interioridade mesma do sujeito humano, tal como acontece na vida de Edith Stein. A partir da experiência pessoal interior da autora, o fenômeno religioso altera também o trajeto de sua vida social e mundo circundante na medida em que o vivencia.

Este ensaio objetiva apresentar uma breve síntese do conceito de individuação no pensamento de Edith Stein e apresentar sua trajetória pessoal em momentos de individuação, a fim de demonstrar que se pode perceber o processo em sua própria experiência pessoal. Se, como é dito, a individuação é um processo que encaminha o ser da pessoa a uma plena realização de si mesmo, a narrativa própria deste processo dá a conotação de uma personalização da consciência de si, como o faz Stein ao elaborar sua autobiografia.

Espera-se, a partir do modelo de vivência de Edith Stein, poder apontar para a reflexão de que tal processo também acontece na fenomenologia da vida de cada ser humano, como transcendência em direção ao sentido da vida.

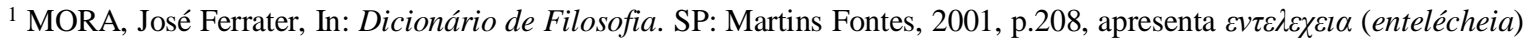

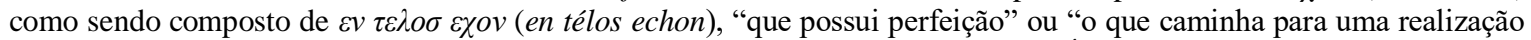
perfeita, plena de si”, termo iminentemente filosófico como atualização; CHAUÍ, M. In: Introdução à História da Filosofia, Vol. 1, SP: Companhia das Letras, 2002, p.500, mostra seu uso por Aristóteles como "o que faz uma potência ser atualizada; a atualidade completa de um ser; a atualização como realização da finalidade que um ser possui por natureza".
} 


\section{Conceito de individuação em Edth Stein}

Enquanto etimologia, o termo "indivíduo" pode ser dito tanto como uma unidade visível e indivisível na multiplicidade de objetos, individum (não-dividido); quanto também um ser único de uma espécie e de um gênero específico, hominis (homem). Então, individuação tem a ver com uma visão de metafísica da natureza e causalidade, como também de uma ontologia da essência e do ente, e ainda, com um processo de enticidade do ser do ente na forma de sua representação e estruturação no mundo. Alguns termos greco-latinos intercambiáveis para a definição do termo são: átomo, atomon, como o "indivisível, o uno, o in-dividuo", num sentido físico e ôntico de ente, na filosofia pré-socrática; hypokéimenon (subsistente), como designação do homem em seu processo subjetivo de tonar-se "sujeito", nos sistemas platônico e aristotélico; e hypóstasis, persona, como "pessoa, sujeito, indivíduo", num sentido metafísico e ontoteológico do ser, na filosofia escolástica, especialmente tomista.

Como ontologia, o conceito de individuação toca na questão da singularidade da pessoa humana, que se constitui a partir de um princípio, principium individuationis; tal ideia vem da cultura medieval, da busca de se formular uma filosofia mais precisa do sujeito em vista de uma ciência do humano e uma psicologia da pessoa. Assim, poderíamos ver o conceito desde a Antiguidade do âmbito da metafísica e entrar na Idade Média no debate escolástico entre os sistemas platônico e aristotélico pela elucidação da constituição do indivíduo, lançando as bases da dialética entre objetividade e subjetividade do sujeito, todavia não é aqui a intenção deste trabalho nem o espaço para tal.

O conceito de individuação, assim, tem suas raízes na metafísica aristotélica, enquanto estudo do processo mesmo da entidade, do tornar-se ente e do ente tornar-se si mesmo. De modo geral, em termos aristotélicos, primeiro diz respeito ao vir-a-ser (devir) de uma mesma substância (ousía, essentia) de onde vem e para onde voltam todos os seres (ontá, entes). Durante a vida de cada individuo, seu ser se processa na existência fática do mundo numa contínua atualização (entelécheia) de potência (dynamis) em ato (energéia), até o fim último de uma "perfeição" (télos) já inscrita no composto do ser.

Pensar em ontologia da individuação, então, é pensar no ser da natureza universal de onde advêm os entes individuais. A síntese de epistemologia do conceito que Edith Stein faz segue este roteiro desde suas raízes na antiguidade clássica em termos e expressões gregas, depois passando à sua apreensão pela filosofia cristã medieval no estudo do princípio que o orienta o processo de entidade (principium individuationis), especialmente na metafísica cristã escolástica de Tomás de Aquino. 
Esta apreensão do estudo do ser (ens, essentia) da tradição aristotélica pela metafísica medieval é fundamental no pensamento de Edith Stein, quando de sua passagem da fenomenologia à metafísica cristã e seu encontro com a ontologia tomista. Portanto, Edith Stein pensa a individuação através da tradição ontológica aristotélico-tomista, principalmente através dos estudos fenomenológicos que realiza em suas atividades acadêmicas no período de 1922-32, após sua conversão católica e o conhecimento das obras de Tomás de Aquino.

Edith Stein aborda a questão da ontologia da individuação, enquanto fundamentos filosóficos sobre o ser, fazendo conexão entre a fenomenologia husserliana e a metafísica escolástica aristotélico-tomista. $\mathrm{O}$ tema percorre quase todas as suas obras de relevo.

Desde o início o objeto de estudos visado por Edith Stein foi o mundo subjetivo da pessoa humana, portanto, um espaço ôntico de um mundo ontológico, tanto individual quanto coletivo. A influência lhe advém das aulas de Husserl sobre o clássico problema da "separação" e da "participação" entre sujeito e mundo, entre "Natureza e espírito", posto deste Platão, mas cuja fissura se aprofundou a partir de Descartes e Kant, donde advém sua tese: "Durante suas aulas do curso 'Natureza e espírito', Husserl havia dito que um mundo exterior objetivo podia ser apreendido apenas intersubjetivamente, ou seja, por uma pluralidade de indivíduos que conhecem e que comunicam entre si" (STEIN, 2018, p.345). Para isso, diz ela, "um pressuposto requerido era ter uma experiência dos outros indivíduos. Husserl chamava essa experiência de empatia (intropatia)... eu queria explorar o que era a empatia" (p.345).

Os primeiros textos de Stein têm a tônica e seguem a ontologia fenomenológica de Husserl, dividida em ontologia formal e ontologia material. Segundo Alfieri (2014, p.35), Husserl considerava a metafísica escolástica como tendo uma abordagem extrafenomenológica. Primeiramente através da filosofia fenomenológica, ao estudar a estrutura ôntica do individuo humano, partindo do Eu - centro ordenador da consciência, Edith Stein pode chegar ao núcleo (Kern) da personalidade, ponto central e inédito de sua ontologia, tópico desenvolvido deste a tese e em quase todas as suas obras selecionadas.

A ideia de um núcleo no centro espiritual da personalidade, que orienta todo o processo de desenvolvimento, citado desde o texto de sua tese, torna-se o ponto mais relevante do conceito de individuação e singularidade da pessoa nos textos de Edith Stein.

Quanto ao princípio e processo da individuação, Edith Stein, em sua tese Sobre o problema da empatia (1916/2005, p.118s), diz que a individuação tem um centro orientador da consciência do individuo que é seu "eu" puro. Todavia, já no texto de Contribuições para a fundamentação filosófica da psicologia e ciências do espírito (1922/2005, p. 436s), afirma 
que a potência do ser vem do "centro" da alma (Kern), que é o núcleo espiritual do ser. Depois, na Estrutura da Pessoa Humana (1932/2013, p.625s), sob plena base tomista, ela afirma que a "alma" (anima), com seu núcleo (“alma da alma"), é a "forma” do corpo e o fator que individua. Mais tarde, em Introdução à Filosofia (1931/2005, p.809s), a individuação se orienta de dentro para fora a partir do núcleo, que guarda em si a essência (eidós) do individuo pela qual adquiri sua singularidade.

Esta fundamentação ontológica da individuação está na passagem da filosofia antropocêntrica da fenomenologia de Husserl para a filosofia antropoteológica da metafísica cristã, primeiro em Tomás de Aquino e mais tarde um pouco em Santo Agostinho e Duns Escoto, fundamentos advindos após sua experiência de conversão. É neste contexto que Stein passa a investigar o conceito de individuação, sob a dupla dimensão ôntica e ontológica, ou a estrutura interior e exterior do ser humano, tanto na sua dimensão individual quanto coletiva.

Nestes textos germinais o esboço já é traçado. Podemos dizer que Stein procede de dentro para fora os estudos, pois quando começa estudar o conceito de individuação propriamente ela já possui uma bagagem grande de investigações da estrutura da pessoa humana, como culminará no texto com este título. Com razão afirma Francesco Alfieri (2014, p.36, nota 13): "Podemos dizer que a vida de Edith Stein começa efetivamente a mudar com o ensino de filosofia em 1932-1933, em Münster, onde ela se ocupa da formação de jovens". Tempo da produção de grandes textos como a Introdução à Filosofia (1931) e a Estrutura da Pessoa Humana (1932). Reconhece-se realmente neste período certa "virada" no pensamento de Stein, todavia não notamos em suas obras grandes mudanças de rumo de pensamento, apenas acréscimos ao esboço traçado nas duas grandes obras fenomenológicas já referidas (Empatia e Psicologia) e novos desafios como a fundamentação daquilo que chamamos de uma ontologia do espírito nas obras subsequentes Ato e Potência (1933) e Ser finito e ser eterno (1936). São estes textos, mais especificamente, que tratam da individuação.

Podemos afirmar também que, quando Stein adentra o terreno da investigação sobre a individuação, ela articula sempre as duas linhas: fenomenológica e escolástica; esta investiga a estrutura do ser a partir de sua fonte externa (ontológica) na natureza espaço-temporal do vir-aser dos entes, que é marca a tradição clássica antiga e medieval, aquela investiga a estrutura interna (ôntica) na natureza consciente e espiritual da realização do ser em si mesmo. Assim, podemos dizer que esta é uma visão arrojada de Edith Stein, a persistência da investigação do individuo como uma unidade ou uma totalidade acabada em si, porém sempre constituído em duas dimensões: natureza e espírito, tal como havia ouvido no seminário de Husserl e que certamente a guiou até o fim de seus estudos. Portanto, não só uma consideração espaço-temporal (natureza), mas também transcendente (espirito) do ser. 


\title{
Experiência religiosa de Edith Stein
}

Pensamos ser possível demonstrar a individuação como processo revisando momentos da experiência existencial de Edith Stein, no intuito de apontar uma fenomenologia da significação de fatos da individuação nesta intensa vita brevis, mas plena da consciência de si.

\begin{abstract}
Há que se acentuar que o tal ser-consciente-de-si-mesmo existe unicamente para a alma, na qual temos reconhecido o centro e a singularidade da pessoa empírica que vive nela. Para a psique e para suas qualidades - também para aquelas que têm seu fundamento na singularidade pessoal: o caráter - não existe possibilidade alguma de semelhante captação; para elas é necessária sempre uma objetivação do vivencial (STEIN, 1931/1998, p.228).
\end{abstract}

Um primeiro momento da individuação de Edith Stein pode ser apontado na importância de sua família e estudos para a formação de sua personalidade. Edith Theresa Hedwing Stein nasceu em Breslau na Alemanha, no dia 12 de outubro de 1891, caçula entre onze filhos de pais judeus, no dia do Yom Kippur, maior festa do calendário judaico. Stein se fundamenta na família e na identificação com a mãe, à qual se volta ao final da vida como meio de compreender a si mesma. A própria Stein no prefácio de sua Autobiografia, História de uma família judia (1933-39), apresenta seus relatos como a história da própria mãe, como se se redimisse da discordância e distanciamento que tomou dela apesar do apego de alma.

\footnotetext{
Em princípio era minha intenção escrever as memórias de minha mãe. Ela era sempre incansável em seus relatos e também eu não podia esperar que em sua avançada idade pudesse escrever pessoalmente - tem 84 anos - eu queria formalmente contar e restituir a sua palavra o mais fielmente possível. (...) Nestas páginas que se seguirão darei a preferência às breves anotações coligidas nas conversações com minha mãe. Daqui deve resultar uma biografia de minha mãe, tal como eu possa descrevê-la (STEIN, 1933-39/1992, p.24).
}

Desde o ingresso na universidade em 1911, Edith Stein experimenta na liberdade acadêmica uma crescente inquietação pela verdade. A verdade se torna sua busca de vida e tema de pesquisa, de modo que ela é considerada a filósofa da busca da verdade. Ales Bello diz que seu contato com a filosofia ao encontrar-se com Husserl em Göttingen, aguça sua paixão pela verdade (ALES BELLO, 2014, p.31). 
Ales Bello (2014, p.31), citando a Autobiografia, mostra que este primeiro momento de busca pela verdade produz certo embate entre racionalidade e religião: "Os limites dos preconceitos racionalistas, nos quais eu havia crescido sem saber, caíram, e o mundo da fé despontou improvisadamente diante de mim".

Um segundo momento na sua individuação certamente é o encontro com a fenomenologia, que se dá de 1913-1916 em Gottinga, quando entra para o curso de filosofia e conhece a o mestre Edmund Husserl, e que se estende depois com participações no círculo de estudos de fenomenologia até 1922, ano de sua conversão. A fenomenologia, novidade filosófica do século XX, fornece-lhe fundamento e método para esta indagação maior de sua alma sobre a verdade. Husserl via o indivíduo não só sujeito (subiectum), mas também um ser para outrem (objectum), que se traduz em "atos do sujeito" para o outro e o mundo. Husserl não desconsidera o mundo externo em favor da primazia do mundo interno do sujeito como Descartes e Kant. Mas, como conhecer a "realidade" do mundo?

Ângela Ales Bello (2010, p.6) diz que o método fenomenológico abrira uma abrangência de possibilidades de pesquisas à Edith Stein, principalmente às questões da percepção do sujeito humano. O método da epoché dá esta condição porque coloca toda a percepção da consciência à “experiência do vivido" (Erlebnisse). O entusiasmo de Edith Stein pela nova descoberta a leva a participar do grupo de estudos de filosofia em torno da fenomenologia, onde conhece vários filósofos de fama, como Max Scheler, que também era católico, Adolph Reinach Hedwig ConradMartius, que eram protestantes, Martin Heidegger, entre outros. Seu interesse era conhecer a essência da pessoa, mas o método fenomenológico se aplicaria à pesquisa de tal tema?

Um terceiro momento de individuação pode ser vista então nesta pesquisa que se constituiu em sua tese da empatia e na experiência empática de autodoação, entre os anos 1915-17, sob a orientação de Husserl. No meio de sua pesquisa, interrompe seus estudos filosóficos e se oferece de voluntária no Hospital Militar da Cruz Vermelha, na Áustria, entre 1915-16, por ocasião da Primeira Guerra, onde serve por meses como enfermeira de centenas de feridos de guerra. Apesar de sua característica timidez, este exercício de autodoação lhe proporciona uma vivência de empatia, pela possibilidade de encontro com o outro no âmbito da dor e do amor de compaixão. Segundo José Pedra, a própria Edith Stein a tal experiência: "Pessoas voluntárias, em tais lugares de dor permanente, podiam encontrar um amplo campo para exercer o amor ao próximo" (PEDRA, 1998, p.17).

A experiência empática de compaixão despertou-lhe o amor escondido no coração por baixo da crítica racional. A questão da intropatia, tal como Husserl a tinha posto, parecia-lhe a chave de interpretação da pessoa humana. Ao voltar da Guerra retoma sua tese de doutorado e a defende Cum Laude em 1916, Sobre o Problema da Empatia, na qual investigava a experiência do "ato empático" como "intencionalidade da consciência" no conhecimento do outro, tema "que levava muito dentro do coração". 
Um quarto momento da individuação em Edith Stein pode ser visto em sua conversão ao cristianismo. Após retornar à universidade e defender sua tese em Julho de 1916, Stein continuou secretária de Husserl e participante de seu grupo de intelectuais estudiosos no Circulo de Gottinga. Um destes assistentes, amigo de Edith, era o filósofo protestante Adolf Reinach, que ao final de 1917 foi vitimado pela Guerra. Ela é chamada a cuidar da casa e organizar os escritos do falecido, e aí trava conhecimento sobre a fé em Cristo da viúva Anna: "Foi esse meu primeiro encontro com a Cruz, minha primeira experiência da força divina que da cruz emana e se comunica aos que a abraçam" (PEDRA, 1998, p.25).

A inquietação do espírito investigativo encontra consolo na luz da fé. Em 1919, libera-se do mestre Husserl e volta de Freiburg à casa de fazenda do casal de amigos Conrad-Martius, em Bergzaben, onde se reúne um círculo de filósofos cristãos. Numa noite de insônia de 1921, ao ler na biblioteca o livro Vida de Santa Tereza d'Ávila, já pela manhã tem súbita intuição de descoberta da verdade (SCIARDINI, 1999, p.21).

A experiência de conversão muda os rumos da trajetória da vida e pensamento de Edith Stein. Ela diz que "Desde que no verão de 1921 caiu em minhas mãos a "Vida" de nossa Santa Teresa, pôs fim a minha larga busca da verdadeira fé" (STEIN, 2018, p.543). Mais tarde, apos esta experiência interior: "Chega o momento em que afinal se realiza aquilo que era tão esperado e almejado: de repente, inesperadamente, a alma peregrina encontra o olhar dos divinos olhos" (STEIN, 2013, p.196). Conforme José Pedra (1998, p.32), consta no livro da igreja católica local de Bergzaben o registro feito pelo pároco Eugênio Breitlig: "Em primeiro de Janeiro do ano do Senhor de 1922, Edith Stein, de trinta anos de idade, doutora em filosofia, foi batizada".

Um quinto momento de individuação pode ser visto no período que vai de 1922-1933, como encontro com a metafísica cristã , após sua conversão, ao ingressar no movimento de intelectuais católicos no círculo tomista do mosteiro de Beuron. Este é um fértil período de academicismo, onde pelas aulas ministradas passa a aproximar as ciências naturais da psicologia e pedagogia à ciência do espírito, e à teologia.

Neste período Stein se dedica ao conhecimento da individuação e da estrutura da pessoa humana: "Um dos temas centrais da filosofia de E. Stein é o da pessoa e, inclusive, poderíamos afirmar, que há um Personalismo Steiniano. Ela concebe uma estrutura ôntica da pessoa. Os conceitos de 'indivíduo' e 'individualidade' fazem referência aos distintos aspectos desta estrutura” (FAITANIN, 2003, p.174). 
Aproximar a fenomenologia de Husserl e a metafísica de Aquino é um feito inédito de Edith Stein. Em 1929 publica no jornal de fenomenologia o artigo Que é filosofia? Um diálogo entre Edmund Husserl e Tomás de Aquino, que causa impacto no círculo de Husserl e no meio filosófico e teológico. Segundo Faitanin (2003, p.175): "A fascinação de saber como o "eu" percebe o mundo fenomênico lhe fez assentar o interesse sobre a estrutura da consciência e o modo como esta estrutura da consciência percebe intencionalmente o nômeno ao lidar com o fenômeno".

Um sexto momento de individuação pode ser considerada ainda como sua experiência de amor quando do ingresso no trabalho de educação pedagógica, entre 1932-34, um período de “educação em amor" tanto aos outros e como de si mesma, até sua rejeição na escola por ser judia, fato que a leva a dar sua entrada como freira carmelita no mosteiro do Carmelo de Colônia, em 15 de abril de 1934. Segundo Clélia Peretti (2010), na experiência empática no exercício educativo da pedagogia, psicologia e teologia, Stein descobre as relações entre a espiritualidade e a alteridade construída na relação com uma nova perspectiva de revalorização do outro (altro), quer se dá através da vida comunitária, em termos de relações não mais "egológica", mas "altrológica" com valorização da pessoa do outro.

Como sétimo é último momento na individuação de Edith Stein destacamos finalmente $o$ tornar-se si-mesmo em espírito, que se dá na parte final de sua vida em clausura no Mosteiro do Monte Carmelo em Colônia, como preparo ao desafio final do holocausto na crueldade do nazismo em Auschwitz Birkenau em 1942.

Em sua experiência mística Stein escreve sobre o tema da espiritualidade. Sua última obra A Ciência da Cruz (2013) é uma abordagem teológica sob a tentativa inédita de abordar pelo método fenomenológico a questão da mística, como uma via possível a todos os que desejam o apuro da individuação no espírito. Para Ales Bello (1998, p.318-320) Stein se utiliza da arte como via simbólica mais adequada para interpretar as profundas da alma, como a poesia de São João da Cruz, as crônicas, a lírica da liturgia e a contemplação, expostas no Castelo Interior de Tereza de Ávila. A cruz se torna imagem símbolo de sua individuação, tal como a experimentara São João da Cruz e Teresa de Ávila: “...a vida mística nada mais é do que o desenvolvimento das três virtudes teologais - ou seja todos os cristãos são chamados ao essencial, à união com Deus. E isto não é extraordinário" (STEIN, 2013, p.320). 
Por toda a vida Edith Stein buscou a verdade: “Assim, busco achegar-me ao altar de Deus. Aqui não está em questão eu e minhas preocupações extremamente pequenas, mas o grande sacrifício da reconciliação" (STEIN, 2012, p.113).

Em 09 de agosto de 1942, a irmã Teresa Benedita da Cruz, Edith Stein, morreu em Auschwitz. Por seu heroísmo cristão, no dia 11 de outubro de 1998, foi canonizada pelo Papa João Paulo II, sob o nome de Santa Teresa Benedita da Cruz.

\section{Considerações finais}

Como foi possível ver, a própria experiência existencial da autora serve de exemplo de demonstração do processo de individuação, como um caminho inexorável de consciência de si e busca de dar sentido à vida pela busca da verdade de si, cuja narrativa é já a transformação de uma vida material finita em direção à transcendência para um sentido infinito do ser.

Edith Stein considera a pessoa humana na sua estrutura e inclui a dimensão espiritual na realização (entelécheia) de sua individuação, buscando fundamentos ontoteológico tanto na fenomenologia de Husserl, como na metafísica cristã de Aquino, fazendo aplicar o método fenomenológico ao fenômeno da experiência pessoal e religiosa. Ela aponta o personalismo como melhor forma para uma abordagem ontoteológica deste processo, pois no processo de vida histórica de todo o ser humano há a possibilidade de encontro com o Ser divino.

Ela reafirma sua fé a partir da própria experiência: “Assim, busco achegar-me ao altar de Deus. Aqui não está em questão eu e minhas preocupações extremamente pequenas, mas o grande sacrifício da reconciliação." (STEIN, 2012, p.113). A cruz, ainda que como "caminho mais escuro", torna-se a imagem simbólica de sua individuação, tal como a encontra em São João da Cruz e Santa Tereza d'Ávila: “O caminho mais escuro é o mais seguro. [...] Quem não quer outra coisa, senão Deus, não anda em trevas, por muito obscurecido e pobre que seja...” (STEIN, 2013, p.225).

Portanto, a fenomenologia da experiência religiosa se dá a partir da alma do sujeito e no processo mesmo de sua individuação, de tal modo, que impregna toda sua história e seu mundo, tornando a própria vida uma obra de arte. Também foi possível verificar, ainda que em breve síntese, que a fenomenologia, na qual a autora apoia seu pensamento, e o método fenomenológico são bases suficientes para a pesquisa do tema da individuação da pessoa.

Vimos também na história da experiência religiosa de Edith Stein, que a própria compreensão da autoexperiência espiritual no decurso da própria existência, exige o contínuo autoconhecimento e que para isto o método fenomenológico é apropriado e o que Edith Stein faz e prova que, nenhuma experiência religiosa é suficiente como mera experiência fática sem que seja subjetivamente transformada em interioridade, sabedoria e sentido da vida. 
A narrativa da história existencial é uma forma de dar sentido à própria experiência, colocando os fatos da vida e o caminho percorrido numa ordem lógica de significações.

Por fim, a coroação de sua trajetória de vida e dedicação à busca da verdade em sua própria experiência, que culmina em holocausto, enquanto canonização, abre espaço para o reconhecimento de seu heroísmo como exemplo de possibilidade de busca de transcendência

\section{Referências}

ALFIERI, Francesco. Pessoa humana e singularidade em Edith Stein: uma nova fundação da antropologia filosófica. Trad Clio Francesca Tricarico. SP: Perspectiva, 2014.

ALLES BELO, Angela. A Paixão pela Verdade. Curitiba: Juruá, 2014.

ALLES BELO, Angela. A questão do sujeito: Edmund Husserl e Edith Stein. Revista Eletrônica Anais IV SIPEQ - ISBN - 978.85.98623.04-7. SP: Unesp, 2010. Disponível: www.sepq.org.br/IVsipeq/anais/index.html. Acesso em: 10/09/14.

CHAUÍ, Marilena. Introdução à História da Filosofia: dos pré-socráticos a Aristóteles. 2.ed. SP: Companhia das Letras, 2002. Vol 1.

FAITANIN, Paulo. A individuação da pessoa em Edith Stein: o legado de Husserl e de Tomás de Aquino. Revista Coletânea, Ano II, No 4, 2003. Mosteiro S. Bento, RJ.

MORA, José Ferrater. Dicionário de Filosofia. Trad Roberto L. Ferreira \& Álvaro Cabral. SP: Martins Fontes, 2001.

PEDRA, José A. Edith Stein: uma santa em Ausschwitz. Cuitiba: Rosário, 1998.

PERETTI, Clélia. Edith Stein e as questões de gênero: perspectiva fenomenológica e teológica. Tese de Doutorado. São Leopoldo: EST/PPG, 2010.

SCIARDINI, Patrício. Edith Stein. SP: Loyola, 1999.

STEIN, E. La estrutura de la persona humana. Madrid: Biblioteca de Autores Cristianos, 2007.

STEIN, E. Ser finito e Ser eterno. Obras Completas, III - Escritos Filosóficos. Vitoria: El Carmem \& Madrid: Ed. de Espiritualidad \& Burgos: Monte Carmelo, Espanha, 2007.

STEIN, E. O que é filosofia? Um diálogo entre Edmundo Husserl e Tomás de Aquino. Scintilla - Revista de Filsofia e Mistica Medieval. ISSN 1806-6526 - Curitiba: Scintilla, vol. 2, n. 2, p. 207-364, jul./dez. 2005. Acessado em 08/12/14 e disponível: http://www.saoboaventura.edu.br/galeria/getImage/45/4773138785371750.pdf.

STEIN, E. A Ciência da Cruz. 7.ed. Trad D. Beda Krause. SP: Loyola, 2013.

STEIN, E. Teu coração deseja mais: reflexões e orações. Trad Enio P Giachini. RJ: Vozes, 2012.

STEIN, E. Vida de uma família judia e outros escritos autobiográficos. SP: Paulus, 2018.

STEIN, E. Cartas. Obras Completas, I. Vitoria: El Carmen \& Madrid: Editorial de Espiritualidad \& Burgos: Monte Carmelo, Espanha, 2002.

STEIN, E. Sobre el problema de la empatía (1916). Obras Completas, II. Vitoria: El Carmen \& Madrid: Editorial de Espiritualidad \& Burgos: Monte Carmelo, Espanha, 2005a.

STEIN, E. Contribuciones a la fundamentación filosófica de la psicologia y de las ciências del espíritu (1922). Obras Completas, II. Vitoria: El Carmen \& Madrid: Editorial de Espiritualidad \& Burgos: Monte Carmelo, Espanha, 2005b. 
STEIN, E. Introdución a la filosofia (1931). Obras Completas, II. Vitoria: El Carmen \& Madrid: Editorial de Espiritualidad \& Burgos: Monte Carmelo, Espanha, 2005c.

STEIN, E. Acto y Potencia: estúdios sobre uma filosofia del ser (1933). Obras Completas, III. Vitoria: El Carmen \& Madrid: Editorial de Espiritualidad \& Burgos: Monte Carmelo, Espanha, 2007a.

STEIN, E. Ser finito y ser eterno: ensayo de una ascensión al sentido del ser (1936). Obras Completas, III. Vitoria: El Carmen \& Madrid: Editorial de Espiritualidad \& Burgos: Monte Carmelo, 2007b.

STEIN, E. L'Empatia. Trad Michele Nicoletti. Milano/Itália: Franco Angelli, 1992.

STEIN, E. Introduzione alla filosofia. Cura di Angela Ales Bello e Trad Anna M. Pezzela. Roma: Cità Nuova Editrice, 1998.

STEIN, E. Storia de una famiglia ebrea. Trad Gyorgy Szokoly. Roma: Cità Nuova Editrice, 1992.

STEIN, E. Essere finito e essere eterno: per una elevazione al senso dell'essere. Cura di Angela Ales Bello e Trad Luciana Vigone. Roma: Cità Nuova Editrice, 1988.

STEIN, E. La estruttura della persona umana: corso di antropologia filosófica. 